\title{
Strategies to improve follow-up of children after surgery for cataract: findings from Child Eye Health Tertiary Facilities in sub-Saharan Africa and South Asia
}

${ }^{1}$ Kilimanjaro Centre for Community Ophthalmology, Moshi, Tanzania

${ }^{2}$ Light for the World, Veenendaal, The Netherlands

${ }^{3}$ Kilimanjaro Centre for Community Ophthalmology, Division of Ophthalmology, H53 OMB Groote Schuur Hospital, University of Cape Town, Cape Town, South Africa

Correspondence:

P Courtright, Kilimanjaro Centre for Community Ophthalmology, Division of Ophthalmology, H53 OMB Groote Schuur Hospital, University of Cape Town, Cape Town 7708,

South Africa

Tel: +27 72677 2762;

Fax: +27214066218.

E-mail: pcourtright@kcco.net

Received: 29 February 2016 Accepted in revised form: 4 July 2016 Published online: 29 July 2016

\begin{abstract}
Purpose We sought to conduct a systematic literature review on follow-up of children with ocular surgical management (primarily childhood cataract) in developing countries. Second, we sought to determine the current practices regarding follow-up for clinical, optical, low vision, rehabilitation, and educational placement among children receiving surgical services at Child Eye Health Tertiary Facilities (CEHTF) in subSaharan Africa (SSA) and South Asia.

Methods A systematic literature review was conducted. Separately, we conducted a crosssectional study among CEHTF in SSA and South Asia (India, Nepal, and Bangladesh) to assess current capacities and practices related to follow-up and educational placement. Results The articles that met the systematic review eligibility criteria could be grouped into two areas: factors and strategies to improve post-operative follow-up and educational placement of children after surgery. Among the 106 CEHTF in SSA and South Asia, responses were provided by 75 CEHTF. Only $59 \%$ of CEHTF reported having a Childhood Blindness and Low Vision Coordinator; having a coordinator was associated with having appropriate follow-up mechanisms in place. Educational referral practices were associated with having a lowvision technician, having low-vision devices, and having donor support for these services. Conclusions The systematic literature review revealed evidence of poor follow-up after surgical interventions for cataract and other conditions, but also showed that follow-up could be improved significantly if specific
\end{abstract}

E Kishiki ${ }^{1}, K$ van Dijk ${ }^{2}$ and $P$ Courtright $^{3}$

strategies were adopted. Approaches to follow-up are generally inadequate at most facilities and there is little external support for follow-up. Findings suggest that funding and supporting a coordinator would assist in ensuring that good practices for follow-up (cell phone reminders, patient tracking, and reimbursement of transport) were followed. Eye (2016) 30, 1234-1241; doi:10.1038/eye.2016.169; published online 29 July 2016

\section{Introduction}

Increasing the global knowledge base for planning for childhood eye care services is a top priority in order for children with visual impairment to realize their full visual potential. The body of knowledge on programmatic approaches to paediatric eye care in developing countries has significantly increased in the past 10 years, and evidence suggests that, with the reduction in vitamin A deficiency and measlesrelated blindness, childhood cataract requires increased global attention. ${ }^{1}$

For many years, there has been considerable concern about the low levels of follow-up for distance corrections, optical low-vision devices, and educational placement for children receiving cataract and other ocular surgeries in many developing countries. ${ }^{2,3}$ Initial work in Tanzania identified reasons for poor follow-up ${ }^{4}$ and demonstrated strategies to address these. ${ }^{5}$ There is limited information on educational placement following sight-restoring or sight-improving surgery in children ${ }^{6}$ and existing information suggests that there are considerable challenges in ensuring that children are placed in the most 
appropriate educational setting. ${ }^{7,8}$ We sought to conduct a systematic literature review on follow-up of children with ocular surgical management (primarily childhood cataract) in developing countries. Second,

we sought to determine the current practices regarding follow-up for clinical, optical, low vision, rehabilitation, and educational placement among children receiving surgical services at Child Eye Health Tertiary Facilities (CEHTF) in sub-Saharan Africa (SSA) and South Asia.

\section{Materials and methods}

A systematic literature review was conducted including a search in MEDLINE using the terms "Follow up strategies", "childhood cataract surgery", "phone follow up", "text message", "visual impairment", and "school placement" for articles published in English language from 1 January 2001 to 30 June 2015. We also systematically searched the reference lists of included publications.

Separately, we conducted a cross-sectional study among CEHTF in SSA and South Asia (India, Nepal, and Bangladesh) to assess current capacities and practices related to follow-up. A list of CEHTF in SSA and South Asia was generated by our group with assistance for South Asia from ORBIS International and key personnel in the region. A questionnaire was designed and pretested with one facility; after this it was sent to the heads of CEHTF. The questionnaire included information on staffing, infrastructure, strategies used to improve follow-up, post-operative services provided, and educational placement practices (Supplementary Material). There were two open-ended questions on the survey, the first asking which children were least likely to return for follow-up and the second asking what the barriers to follow-up were. The questions, although related, reflect different perspectives on the same issue of poor follow-up after surgery. Responses to the questions were tallied by topic area. Respondents could provide multiple answers.

The study was approved by the University of Cape Town ethics committee and participants consented to use responses; all data were compiled and reported anonymously.

All CEHTF were contacted at least three times to obtain responses. Colleagues in Nigeria, Bangladesh, Nepal, India, and South Africa did follow-up contact with CEHTF who did not respond to the first two requests. Analysis was undertaken using Stata version 11.0 (College Station, TX, USA). Findings were reported as odds ratios (95\% confidence intervals) and mean values.

\section{Results}

\section{Literature review}

The literature review identified 431 articles; 340 articles were not included after the first review as they did not include any information on follow-up. Among the remaining 91 articles, 25 met the eligibility criteria; all were reviewed and 17 provided information on one or more topics related to post-operative follow-up of children with cataract or other eye surgical conditions. The articles could be grouped into two areas: factors and strategies to improve post-operative follow-up and educational placement of children after surgery.

The first article that addressed the issue of postoperative follow-up was conducted in Tanzania ${ }^{4}$ and included an assessment of the pre-surgical factors that predicted whether children returned for their 2-week and 10 -week follow-ups. On the basis of this work, a second paper ${ }^{5}$ demonstrated the effect of specific strategies to improve follow-up. Similar studies have been conducted in India, ${ }^{9}$ Mexico, ${ }^{10}$ China, ${ }^{11}$ and Nepal. ${ }^{12}$ The findings from these studies suggest a significant range in followup from $21 \%$ in India ${ }^{9}$ to $98 \%$ in Mexico, ${ }^{10}$ most however, being low. Factors associated with poor follow-up included long distance to the surgical facility, ${ }^{4,9,10}$ being a girl, ${ }^{4}$ long delay in presentation, ${ }^{4}$ and cost and poor understanding of the need for follow-up. ${ }^{9}$ Specific followup strategies (use of cell phone as reminders, reimbursing travel, maintaining a tracking sheet, and dedicated counselling) undertaken in Tanzania increased the proportion of children returning for their 10-week followup from 43 to $83 \%$ and gender inequity in follow-up disappeared. ${ }^{5}$ Undertaking a similar approach, a team in Nepal increased the proportion of children returning for post-operative services from 60 to $81 \% .{ }^{12}$ Using a randomized trial approach, a team in China showed that SMS reminders were an effective approach to improve follow-up. ${ }^{11}$

There were only three papers, all from eastern Africa, that addressed educational placement after cataract surgery. ${ }^{6-8}$ There have been a number of surveys in schools for the blind that have noted the possibility of inappropriate educational placement, ${ }^{13,14}$ but only one in which educational placement was the focus of the study. ${ }^{7}$ The findings from these studies suggested that, although children had significantly improved vision postoperatively, they were not often placed in the most appropriate educational environment.

Among the 106 CEHTF in SSA $(n=46)$ and South Asia $(n=60)$, responses were provided by $75(71 \%$ of total questionnaires sent) CEHTF (39 in SSA and 36 in South Asia). The majority of the missing data were from India (23 of 42 CEHTF reported). 


\section{Staffing and facilities}

The CEHTF have been providing services for a median 10 years, ranging from $<1$ to 48 years. All except four facilities reported having an optometrist and all except 11 facilities reported having a low-vision specialist. Only 44 facilities $(58.7 \%)$ reported having a Childhood Blindness and Low Vision Coordinator.

Dedicated children's outpatient rooms were found at $54(72 \%)$ facilities and dedicated paediatric operating theatres were found at $39(52 \%)$ of facilities. Most CEHTF (67; 89.3\%) had an optical shop and 52 facilities (69.3\%) made spectacles in the optical shop. Low-vision rooms were found in $52(69.3 \%)$ of CEHTF.

\section{Follow-up activities undertaken}

All facilities report counselling to improve follow-up. Counselling is done by a wide range of people: childhood blindness coordinators $(25 ; 33.3 \%)$, eye nurses $(26 ; 34.7 \%)$, optometrists $(6 ; 8 \%)$, and other people $(16 ; 21.3 \%)$. Only 29 facilities $(38.7 \%)$ had a system for tracking children and 34 CEHTF (45.3\%) used cell phones for follow-up; 22 facilities (29.3\%) provided reimbursement for transport if needed. Only 20 facilities (26.7\%) reported having donor support for follow-up.

Refractive services (including spectacles) for children were available at $68(90.7 \%)$ CEHTF. In just over half of the cases $(n=39 ; 52 \%)$, some of the costs for distance correction were covered by donors. In only three cases were some costs covered by government, and in 32 cases $(42.7 \%)$, there was no mechanism to cover the costs. Availability of magnifying devices varied. High +spectacles were available at 64 facilities (85.3\%); hand magnifiers at 62 facilities $(82.7 \%)$; stand magnifiers at 52 facilities (69.3\%); and telescopes at 48 facilities (64\%). In half of the facilities, there were no mechanisms to support provision of low-vision devices $(n=37 ; 49.3 \%)$, whereas 30 facilities $(40 \%)$ had support from donors and 5 facilities $(6.7 \%)$ reported support from the government.

Respondents reported that children living far away were the least likely to return for follow-up; this factor accounted for $53(43.4 \%)$ of a total 122 responses (multiple responses allowed). Children from poor families (including poorly educated families) accounted for $17.2 \%$ of responses and older children accounted for $9.0 \%$ of responses. The most common barrier to follow-up reported included indirect costs (eg, transport to hospital, meals, and accommodation for parents) of follow-up; $62(41.3 \%)$ of 150 reports (multiple responses allowed). This was followed by distance (25.3\%) and lack of knowledge, or negligence by parents (26.0\%). The ranking of responses to both questions was the same for CEHTF in Africa and South Asia.

\section{Educational placement activities}

For school-age children, educational placement is reported to be discussed with parents in 60 facilities $(80 \%)$ and with teachers in 12 facilities $(16 \%)$. Children have different educational needs and CEHTF would be expected to have similar referral patterns if all services were available, and CEHTF staff utilized the options appropriately. This was not the case as the CEHTF refer children to schools for the blind $(n=57 ; 76 \%)$ and into mainstream schools $(n=47 ; 62.7 \%)$ more frequently compared with annexes or resource centres $(n=27 ; 36 \%)$. Some respondents $(n=27 ; 36 \%)$ did not know if children at schools for the blind or annexes were examined prior to the enrolment. Only 23 CEHTF (30.7\%) reported that children were assessed clinically prior to the enrolment; 25 CEHTF (33.3\%) said that children were not examined prior to the enrolment. Most CEHTF $(n=48 ; 64 \%$ ) reported that there was an educational facility for children with other disabilities and 46 reported $(61.3 \%)$ that there was a rehabilitation facility for children with other disabilities. There were significant differences between CEHTF in SSA and South Asia with South Asian CEHTF, generally more likely to have the staffing complement, facilities, strategies to improve follow-up, and follow-up services for children compared with the SSA CEHTF (Table 1).

\section{Factors associated with good follow-up and referral for educational placement}

In the earlier study of CEHTF in Africa, ${ }^{15}$ it was noted that predictors of productivity (number of children receiving surgery per year) were related to manpower, in particular, having a dedicated optometrist, low-vision technician, Childhood Blindness and Low Vision Coordinator (henceforth referred to as the "Coordinator"), and a dedicated anaesthetist. Having a Coordinator is still uncommon, particularly in SSA, yet CEHTF with a Coordinator are more likely to have strategies to improve follow-up, donor support, and plans for educational placement (Table 2). Having a low-vision technician was not associated with having any specific strategies to improve follow-up. Among the 75 institutions, $25(33.3 \%)$ have support from donors (external or government) for both spectacles and lowvision devices, whereas $26(34.7 \%)$ have no mechanism of support for either spectacles or low-vision devices. The remaining CEHTF have a mix of support or no support.

Analysis of the factors associated with referral to mainstream schools and schools for the blind, and/or annexes was undertaken. Although referral patterns would be expected to match the needs of children, of the 47 CEHTF that referred to mainstream schools, 40 (85.1\%) 
Table 1 Comparison of findings from CEHTF in sub-Sahara Africa and South Asia

\begin{tabular}{|c|c|c|c|}
\hline & $\begin{array}{c}\text { Sub-Saharan Africa } \\
\mathrm{N}=39 \\
\mathrm{n}(\%)\end{array}$ & $\begin{array}{c}\text { South Asia } \\
\mathrm{N}=36 \\
\mathrm{n}(\%)\end{array}$ & $\begin{array}{c}\text { Odds ratio }(95 \% \mathrm{CI}) \\
\text { P-value }\end{array}$ \\
\hline \multicolumn{4}{|l|}{ Personnel } \\
\hline \multicolumn{4}{|l|}{ Optometrist } \\
\hline Present & $35(92.1)$ & $36(100)$ & Cannot calculate \\
\hline Absent & & $3(7.9)$ & 0 \\
\hline \multicolumn{4}{|l|}{ Low-vision technician } \\
\hline Present & $31(79.5)$ & $33(94.3)$ & $0.23(0.05-1.19)$ \\
\hline Absent & $8(20.5)$ & $2(5.7)$ & $P=0.06$ \\
\hline \multicolumn{4}{|c|}{ Childhood Blindness and Low Vision Coordinator } \\
\hline Present & $16(41.0)$ & $28(77.8)$ & $0.19(0.07-0.54)$ \\
\hline Absent & $23(59.0)$ & $8(22.2)$ & $P=0.002$ \\
\hline \multicolumn{4}{|l|}{ Facilities } \\
\hline Years in operation & $8.9(8.7)$ & $15.0(9.9)$ & $P=0.006$ \\
\hline \multicolumn{4}{|l|}{ Child outpatient room } \\
\hline Present & $18(46.2)$ & $36(100)$ & Cannot calculate \\
\hline Absent & $21(53.8)$ & 0 & \\
\hline \multicolumn{4}{|l|}{ Paediatric operating theatre } \\
\hline Present & $13(33.3)$ & $26(72.2)$ & $0.19(0.07-0.51)$ \\
\hline Absent & $26(66.7)$ & $10(27.8)$ & $P=0.001$ \\
\hline \multicolumn{4}{|l|}{ Optical shop } \\
\hline Making spectacles & $23(59.0)$ & $29(80.6)$ & $0.35(0.12-0.98)$ \\
\hline Not making specs & $8(20.5)$ & $7(19.4)$ & $P=0.04$ \\
\hline No optical shop & $8(20.5)$ & 0 & \\
\hline \multicolumn{4}{|l|}{ Low-vision room } \\
\hline Present & $19(51.4)$ & 33 (91.7) & $0.09(0.02-0.37)$ \\
\hline Absent & $18(48.6)$ & $3(8.3)$ & $P=0.001$ \\
\hline \multicolumn{4}{|l|}{ Strategies to improve follow-up } \\
\hline Tracking & 7 (17.9) & $22(61.1)$ & $0.14(0.05-0.41)$ \\
\hline No tracking & $32(82.1)$ & $14(38.9)$ & $P=0.001$ \\
\hline Cell phone calls & $13(33.3)$ & $21(58.3)$ & $0.35(0.14-0.91)$ \\
\hline No cell phone calls & $26(66.7)$ & $15(41.7)$ & $P=0.03$ \\
\hline Reimburse travel & $11(28.2)$ & $11(44.0)$ & $0.89(0.33-2.41)$ \\
\hline No reimbursement & $28(71.8)$ & $25(56.0)$ & $P=0.83$ \\
\hline \multicolumn{4}{|l|}{ Donor support for follow-up } \\
\hline Present & $10(25.6)$ & $10(27.8)$ & $0.89(0.32-2.49)$ \\
\hline Absent & $29(74.4)$ & $26(72.2)$ & $P=0.83$ \\
\hline \multicolumn{4}{|l|}{ Counselling done by: } \\
\hline Childhood coordinator & $11(29.7)$ & $14(38.9)$ & \\
\hline Eye nurse & $17(45.9)$ & $9(25.0)$ & \\
\hline Optometrist & $3(8.1)$ & $3(8.3)$ & \\
\hline Other person & $6(16.2)$ & $10(27.8)$ & \\
\hline \multicolumn{4}{|l|}{ Services provided at the CEHTF } \\
\hline \multicolumn{4}{|l|}{ Spectacles can be obtained } \\
\hline Yes & $32(82.1)$ & $36(100)$ & Cannot calculate \\
\hline No & 7 (17.9) & 0 & \\
\hline \multicolumn{4}{|c|}{ Costs for spectacles covered by: } \\
\hline Donor support & $12(31.6)$ & $27(75.0)$ & $0.17(0.06-0.46)$ \\
\hline Government & $2(5.3)$ & $1(2.8)$ & $P=0.001$ \\
\hline
\end{tabular}


Table 1. (Continued)

\begin{tabular}{|c|c|c|c|}
\hline & $\begin{array}{c}\text { Sub-Saharan Africa } \\
\mathrm{N}=39 \\
\mathrm{n}(\%)\end{array}$ & $\begin{array}{l}\text { South Asia } \\
\qquad \mathrm{N}=36 \\
\mathrm{n}(\%)\end{array}$ & $\begin{array}{c}\text { Odds ratio }(95 \% \mathrm{CI}) \\
\text { P-value }\end{array}$ \\
\hline No mechanism & $24(63.1)$ & $8(22.2)$ & \\
\hline \multicolumn{4}{|c|}{ Low-vision devices can be obtained } \\
\hline High mag glasses & $31(83.8)$ & $33(97.1)$ & $0.16(0.02-1.38)$ \\
\hline No high mag glasses & $6(16.2)$ & $1(2.8)$ & $P=0.06$ \\
\hline Hand magnifiers & $28(73.7)$ & $34(100)$ & Cannot calculate \\
\hline No hand magnifiers & $10(26.3)$ & 0 & \\
\hline Stand magnifiers & $19(61.3)$ & $33(97.1)$ & $0.05(0.00-0.40)$ \\
\hline No stand magnifiers & $12(38.7)$ & $1(2.9)$ & $P=0.001$ \\
\hline Telescopes & $18(56.3)$ & $30(91.7)$ & $0.13(0.03-0.51)$ \\
\hline No telescopes & $14(43.7)$ & $3(8.3)$ & $P=0.001$ \\
\hline \multicolumn{4}{|c|}{ Cost of low-vision devices covered by: } \\
\hline Donor support & $14(36.8)$ & $16(47.1)$ & $0.46(0.18-1.18)$ \\
\hline Government support & $1(2.7)$ & 4 (11.8) & $P=0.10$ \\
\hline No mechanism & $23(60.5)$ & $14(41.1)$ & \\
\hline \multicolumn{4}{|c|}{ Educational placement of children } \\
\hline Meet teacher & $4(10.3)$ & $8(22.2)$ & $0.40(0.11-1.46)$ \\
\hline Do not meet teacher & $35(89.7)$ & $28(77.8)$ & $P=0.15$ \\
\hline Meet parent & $31(79.5)$ & $29(80.6)$ & $0.93(0.30-2.90)$ \\
\hline Do not meet parent & $8(20.5)$ & 7 (19.4) & $P=0.90$ \\
\hline \multicolumn{4}{|c|}{ Referral of school-age children to: } \\
\hline School for the blind & $33(86.8)$ & $24(66.7)$ & $3.3(1.03-10.6)$ \\
\hline Not school for blind & $5(13.2)$ & $12(33.3)$ & $P=0.04$ \\
\hline Annex & $12(31.6)$ & $15(41.7)$ & $0.64(0.25-1.67)$ \\
\hline Not annex & $26(68.4)$ & $21(58.6)$ & $P=0.37$ \\
\hline Mainstream school & $20(52.6)$ & $27(75.0)$ & $0.37(0.14-0.99)$ \\
\hline Not mainstream & $18(47.4)$ & $9(25.0)$ & $P=0.04$ \\
\hline \multicolumn{4}{|c|}{ Are children assessed prior to enrolment? } \\
\hline Yes & $12(30.8)$ & $11(30.6)$ & $1.01(0.38-2.70)$ \\
\hline No & $15(38.5)$ & $10(27.8)$ & "no"+"don't know" \\
\hline Don't know & $12(30.8)$ & $15(41.7)$ & Combined \\
\hline \multicolumn{4}{|c|}{ Education facility for children with other disabilities } \\
\hline Present & $28(73.7)$ & $20(57.1)$ & $2.1(0.78-5.62)$ \\
\hline Absent & $10(26.3)$ & $15(42.9)$ & $P=0.14$ \\
\hline \multicolumn{4}{|c|}{ Rehabilitation facility for children with other disabilities } \\
\hline Present & $26(66.7)$ & $20(55.6)$ & $1.60(0.63-4.08)$ \\
\hline Absent & $13(33.3)$ & $16(44.4)$ & $P=0.33$ \\
\hline
\end{tabular}

also referred to schools for the blind or annexes, whereas among the 27 CEHTF that did not refer to mainstream schools, $20(74.1 \%)$ referred only to schools for the blind or annexes; seven CEHTF did not refer at all. If a CEHTF had a low-vision technician, it was 1.86 times (95\% CI 0.48-7.14) more likely to refer children to the mainstream schools. More importantly, if a CEHTF provided lowvision devices (high+spectacles, hand magnifiers, stand magnifiers, and telescopes), it was more likely to refer to the mainstream schools (Table 3). Having donor or government support (as opposed to no support) for lowvision services was also associated with likelihood of referral to the mainstream schools, more so in South Asia than SSA (Table 3).

\section{Discussion}

The systematic literature review revealed evidence of poor follow-up after surgical interventions for cataract and other conditions, but also showed that follow-up 
could be improved significantly if specific strategies (cell phone contact, reimbursing transport, maintaining tracking sheets, and dedicated counselling) were adopted. These strategies require both funding and manpower, generally in the form of a Coordinator.

Table 2 Association between having a Childhood Blindness and Low Vision Coordinator, and likelihood of adopting different strategies to improve follow-up

\begin{tabular}{|c|c|c|c|}
\hline & Has CBLVC & No CBLVC & $\begin{array}{c}\text { Odds ratio }(95 \% \text { CI }) \\
\text { P-value }\end{array}$ \\
\hline \multicolumn{4}{|l|}{ Tracking } \\
\hline Present & $24(54.5)$ & $5(16.1)$ & $6.24(2.02-19.24)$ \\
\hline Absent & $20(45.5)$ & $26(83.9)$ & $P=0.001$ \\
\hline \multicolumn{4}{|l|}{ Cell phone } \\
\hline Present & $26(59.1)$ & $8(25.8)$ & $4.15(1.52-11.33)$ \\
\hline Absent & $18(40.9)$ & $23(74.2)$ & $P=0.004$ \\
\hline \multicolumn{4}{|c|}{ Reimbursement for travel } \\
\hline Present & $20(45.5)$ & $2(6.5)$ & $12.08(2.56-56.98)$ \\
\hline Absent & $24(54.5)$ & $29(93.5)$ & $P=0.001$ \\
\hline \multicolumn{4}{|c|}{ Donor support for follow-up } \\
\hline Present & $17(38.6)$ & $3(9.7)$ & $5.88(1.54-22.36)$ \\
\hline Absent & $27(61.4)$ & $28(90.3)$ & $P=0.005$ \\
\hline \multicolumn{4}{|c|}{ Educational placement of children } \\
\hline \multicolumn{4}{|c|}{ Meet teachers } \\
\hline Yes & $11(25.0)$ & $1(3.2)$ & $10.0(1.22-82.15)$ \\
\hline No & $33(75.0)$ & $30(96.8)$ & $P=0.01$ \\
\hline \multicolumn{4}{|l|}{ Meet parents } \\
\hline Yes & $37(84.1)$ & $23(74.2)$ & $1.83(0.59-5.75)$ \\
\hline No & 7 (15.9) & $8(25.8)$ & $P=0.29$ \\
\hline \multicolumn{4}{|c|}{ Refer to schools to the blind } \\
\hline Yes & $31(70.5)$ & $26(83.9)$ & $0.37(0.11-1.26)$ \\
\hline No & $13(29.5)$ & $4(16.1)$ & $P=0.10$ \\
\hline \multicolumn{4}{|c|}{ Refer to annexes } \\
\hline Yes & $19(43.2)$ & $8(26.7)$ & $2.09(0.76-5.71)$ \\
\hline No & $25(56.8)$ & $22(73.3)$ & $P=0.15$ \\
\hline \multicolumn{4}{|c|}{ Refer to mainstream schools } \\
\hline Yes & $31(70.5)$ & $16(53.3)$ & $2.09(0.79-5.49)$ \\
\hline No & $13(29.5)$ & $14(46.7)$ & $P=0.14$ \\
\hline \multicolumn{4}{|c|}{ Children at schools for the blind assessed before enrolment } \\
\hline Yes & $15(34.1)$ & $8(25.8)$ & $1.49(0.54-4.11)$ \\
\hline No & $18(40.9)$ & $7(22.6)$ & "no"+"don't know" \\
\hline Don't know & $11(25.0)$ & $16(51.6)$ & Combined \\
\hline \multicolumn{4}{|c|}{ Educational referral possible for other disabilities } \\
\hline Yes & $26(59.1)$ & $22(71.0)$ & $0.66(0.25-1.79)$ \\
\hline No & $16(40.9)$ & $9(29.0)$ & $P=0.41$ \\
\hline \multicolumn{4}{|c|}{ Rehabilitation referral possible for other disabilities } \\
\hline Yes & $27(61.4)$ & $19(61.3)$ & $1.0(0.39-2.58)$ \\
\hline No & $17(38.6)$ & $12(38.7)$ & $P=0.90$ \\
\hline
\end{tabular}

The coverage of the CEHTF survey was fairly good (87\% of African facilities, $58 \%$ of South Asian facilities); however, we cannot provide information on how different or similar the responding facilities were from the non-responding facilities.

Compared with the previous survey of CEHTF in $\mathrm{SSA}, 15$ the current assessment demonstrates that the staffing complement and infrastructure has improved greatly in the past 6 years. That said, the staffing and infrastructure findings from the SSA CEHTF were not as supportive of good-quality child eye health services as compared with the South Asian CEHTF. We cannot explain the differences except to note that South Asian CEHTF have, by and large, been established longer and have greater donor support for services provided at follow-up.

Similar to the previous work by Agarawal and colleagues, ${ }^{15}$ having a Coordinator is associated with having effective follow-up mechanisms such as

Table 3 Association between providing low-vision devices and referring to mainstream schools

\begin{tabular}{|c|c|c|c|}
\hline & \multicolumn{2}{|c|}{ Refer children to mainstream schools } & \multirow{2}{*}{$\begin{array}{c}\text { Odds ratio }(95 \% \text { CI }) \\
\text { P-value }\end{array}$} \\
\hline & Yes & No & \\
\hline \multicolumn{4}{|c|}{ Provide high+(magnifying) spectacles } \\
\hline Yes & $43(95.6)$ & $20(80.0)$ & $5.37(0.96-30.12)$ \\
\hline No & $2(4.4)$ & $5(20.0)$ & $P=0.04$ \\
\hline \multicolumn{4}{|c|}{ Provide hand magnifiers } \\
\hline Yes & $43(95.6)$ & $18(69.2)$ & $9.56(1.85-49.47)$ \\
\hline No & $2(4.4)$ & $8(30.8)$ & $P=0.002$ \\
\hline \multicolumn{4}{|c|}{ Provide stand magnifiers } \\
\hline Yes & $35(89.7)$ & $16(64.0)$ & $4.92(1.32-18.39)$ \\
\hline No & $4(10.3)$ & $9(36.0)$ & $P=0.013$ \\
\hline \multicolumn{4}{|c|}{ Provide telescopes } \\
\hline Yes & $35(85.4)$ & $12(52.2)$ & $5.35(1.62-17.60)$ \\
\hline No & $6(16.4)$ & $11(47.8)$ & $P=0.004$ \\
\hline
\end{tabular}

Donor/government support available for low-vision services (all CEHTF)

$\begin{array}{llrc}\text { Yes } & 28(62.2) & 6(23.1) & 5.49(1.84-16.39) \\ \text { No } & 17(37.8) & 20(79.9) & P=0.001\end{array}$

Donor/government support available for low-vision services (South Asia CEHTF)

$\begin{array}{lrrc}\text { Yes } & 18(81.8) & 2(22.2) & 15.75(2.35-106.23) \\ \text { No } & 4(18.2) & 7(77.8) & P=0.002\end{array}$

Donor/government support available for low-vision services (African CEHTF)

\begin{tabular}{lrrc} 
Yes & $10(50.0)$ & $4(23.5)$ & $3.25(0.78-13.48)$ \\
No & $10(50.0)$ & $13(76.5)$ & $P=0.10$ \\
\hline
\end{tabular}


having a tracking register, using cell phone contact for follow-up, and providing reimbursement for travel. There are costs associated with hiring and training a Coordinator, and as noted in our study, CEHTF with a Coordinator are 5.9 times more likely to have donor support.

Approaches to follow-up are generally inadequate at most facilities and there is little external support for followup. The most common follow-up approach was cell phone contact, (still less than half of facilities), followed by tracking (about one-third) and reimbursement.

Approaches to follow-up were weakest in Africa even though there is little difference in donor support between SSA and South Asia. Distances and the indirect costs associated with returning for follow-up remain the main challenges reported by the personnel within CEHTF; this suggests that more proactive efforts at providing support for transport are needed.

Most facilities offered spectacles for children and most also had low-vision devices, although in only about half of the facilities were there mechanisms to support provision of spectacles or low-vision devices for children, particularly in SSA.

Most facilities reported discussing educational placement with parents, but few also discussed it with teachers; referral to mainstream schools without involving the classroom teachers is less likely to lead to successful educational placement.

Referring children with low vision to mainstream school environments, although preferable, may not be possible in all settings, particularly where there are no supportive mechanisms for these children. Nevertheless, the fact that $52 \%$ of CEHTF and $75 \%$ of CEHTF in SSA and South Asia, respectively, refer children to the mainstream schools, indicates that educational attainment opportunities for these children are growing. Most CEHTF reported minimal contact with schools for the blind, as less than one-third of CEHTF knew if children were screened prior to admission to these schools. In the end, providing both the low-vision services and the educational environment will be critical to ensure that children attain the best possible visual and educational outcomes.

Our findings, although limited by the responses received by the CEHTF, particularly those in India, provide valuable insights into how follow-up management is being currently provided in SSA and South Asia. There is considerable scope for improvement of service delivery; this will require investment by government and donors. Given the significant cost ${ }^{16}$ associated with surgical interventions, the effort to obtain good-quality follow-up is minimal. ${ }^{17-19}$

\section{Summary}

What was known before

- Initial work in Tanzania identified reasons for poor follow-up.

- There is limited information on educational placement following sight-restoring or sight-improving surgery in children.

What this study adds

- Systematic literature review on follow-up of children with ocular surgical management in developing countries.

- Determines current practices regarding follow-up for clinical, optical, low vision, rehabilitation, and educational placement among children receiving surgical services at Child Eye Health Tertiary Facilities.

\section{Conflict of interest}

The authors declare no conflict of interest.

\section{Acknowledgements}

This manuscript has been made possible by the support of the American people. We are grateful for the assistance of colleagues in SSA and South Asia, who helped to get the questionnaires completed.

\section{References}

1 Gogate P, Kalua K, Courtright P. Blindness in childhood in developing countries: time for a reassessment? PLoS Med 2009; 6(12): e1000177.

2 Lenhart PD, Courtright P, Wilson ME, Lewallen S, Taylor D, Ventura MC et al. Global challenges in the management of congenital cataract: Proceedings of the International Congenital Cataract Symposium held on March 7, 2014 New York City, New York. J AAPOS 2015; 19(2): e1-e8.

3 Gilbert C, Foster A. Childhood blindness in the context of VISION 2020-the right to sight. Bull World Health Organ 2001; 79: 227-232.

4 Eriksen JR, Bronsard A, Mosha M, Carmichael D, Hall AB, Courtright P. Predictors of poor follow up in children that had cataract surgery. Ophthalmic Epidemiol 2006; 13: 237-243.

5 Kishiki E, Shirima S, Lewallen S, Courtright P. Improving post-operative follow up of children receiving surgery for congenital or developmental cataract in Africa. J AAPOS 2009; 13: 280-282.

6 Mosha M, Courtright P. Change in educational opportunities for children who have had cataract surgery in Tanzania. Vis Impair Res 2008; 10: 44-48.

7 Tumwesigye C, Msukwa G, Njuguna M, Shilio B, Courtright P, Lewallen S. Inappropriate enrollment of children in schools for the visually impaired in east Africa. Ann Trop Paediatr 2009; 29 (2):135-139.

8 Msukwa G, Njuguna M, Tumwesigye C, Shilio B, Courtright P, Lewallen S. Cataract in children attending schools for the blind and resource centers in eastern Africa. Ophthalmology 2009; 116: 1009-1012.

9 Gogate P, Patil S, Kulkarni A, Mahadik A, Tamboli R, Mane R et al. Barriers to follow-up for pediatric cataract surgery in 
Maharashtra, India: how regular follow-up is important for good outcome. The Miraj Pediatric Cataract Study II. Indian J Ophthalmol 2014; 62(3): 327-332.

10 Congdon NG, Ruiz S, Suzuki M, Herrera V. Determinants of pediatric cataract program outcomes and follow-up in a large series in Mexico. J Cataract Refract Surg 2007; 1775-1780.

11 Lin H, Chen W, Luo L, Congdon N, Zhang X, Zhong X et al. Effectiveness of a short message reminder in increasing compliance with pediatric cataract treatment: a randomized trial. Ophthalmology 2012; 119: 2463-2470.

12 Rai SKC, Thapa H, Kandel RP, Ishaq M, Bassett K. Clinical and cost impact of a pediatric cataract follow-up program in western Nepal and adjacent northern Indian states. J AAPOS 2014; 18(1): 67-70.

13 Kaphley D, Marasini S, Kalua K, Naidoo KS. Visual profile of students in integrated schools in Malawi. Clin Exp Optom 2015; 98(4): 370-374

14 Gnyawali S, Shrestha JB, Bhattarai D, Upadhyay M. Optical needs of students with low vision in integrated schools of Nepal. Optom Vis Sci 2012; 89(12): 1752-1756.
15 Agarwal PK, Bowman R, Courtright P. Child eye health tertiary facilities in Africa. J AAPOS 2010; 14: 263-266.

16 Evans CT, Lenhart PD, Lin D, Yang Z, Daya T, Kim YM et al. A cost analysis of paediatric cataract surgery at two child eye health tertiary facilities in Africa. J AAPOS 2014; 18: 559-562.

17 Congdon G, Yan X, Lansingh V, Sisay A, Müller A, Chan V et al. Assessment of cataract surgical outcomes in settings where follow-up is poor: PRECOG, a multicentre observational study. Lancet Glob Health 2013; 1: e37-e45.

18 Lin $\mathrm{H}, \mathrm{Wu}$ X. Intervention strategies for improving patient adherence to follow-up in the era of mobile information technology: a systematic review and meta-analysis. PLoS One 2014; 8: 104-266.

19 Pop-Eleches C, Thirumurthy H, Habyarimana JP, Zivin JG, Goldstein MP, de Walque D et al. Mobile phone technologies improve adherence to antiretroviral treatment in a resourcelimited setting: a randomized controlled trial of text message reminders. AIDS 2011; 25(6): 825-834.

Supplementary Information accompanies this paper on Eye website (http://www.nature.com/eye) 